\title{
Persistent primary hyperparathyroidism: an uncommon location for an ectopic gland - Case report and review
}

\author{
Hiperparatiroidismo primário persistente: glândula \\ ectópica em localização rara - Caso clínico e revisão
}

Sofia Gouveia', Dírcea Rodrigues', Luísa Barros', Cristina Ribeiro', Anabela Albuquerque'2, Gracinda Costa ${ }^{2}$, Manuela Carvalheiro'

\begin{abstract}
SUMMARY
Primary hyperparathyroidism (PHPT) is a common endocrine disorder that mainly affects middleaged women. Patients are usually asymptomatic. The disease might be ascribable to hyperplasia, carcinoma, and single or multiple adenomas. PHPT may be sporadic or familial, the latter comprising multiple endocrine neoplasia type 1 or $2 \mathrm{~A}$, familial benign hypocalciuria hypercalcemia, and hyperparathyroidism-jaw tumor syndrome. The most common causes for persistent PHPT are multiglandular disease, and missed abnormal ectopic or orthotopic parathyroid glands. Imaging localization studies should precede a new surgical intervention. Ectopic parathyroid glands are rarely located at the aortopulmonary window. For diagnosis confirmation, ${ }^{99 m}$ Tc-sestamibi SPECT/CT seems

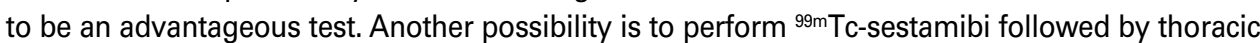
CT or MRI. Parathyroidectomy may be performed by means of median sternotomy, thoracotomy, or video-assisted thoracoscopy. We describe a case of persistent primary hyperparathyroidism due to the presence of an ectopic parathyroid gland found at the aortopulmonary window. As the investigation necessary to clarify the etiology of recurrent nephrolithiasis proceeded, the diagnosis of PHPT was determined. The patient underwent subtotal parathyroidectomy; nevertheless, PHPT persisted. Genetic syndromes that could account for this condition were excluded. Imaging studies available at that time were not able to locate abnormal glands; moreover, the patient refused to undergo surgical exploration. Later, the patient underwent ${ }^{99 \mathrm{~m} T c}$-sestamibi SPECT/CT, which revealed a parathyroid gland at the aortopulmonary window. Arq Bras Endocrinol Metab. 2012;56(6):393-403
\end{abstract}

\section{SUMÁRIO}

O hiperparatiroidismo primário (HPP) é uma endocrinopatia frequente que afeta maioritariamente mulheres de meia-idade e é geralmente assintomática. A doença pode ser atribuível a hiperplasia, carcinoma, adenomas únicos ou múltiplos. 0 HPP inclui formas esporádicas e familiares. As formas familiares englobam neoplasia endócrina múltipla tipo 1 ou $2 \mathrm{~A}$, hipercalcemia hipocalciúrica familiar e síndrome hiperparatiroidismo/tumor mandibular-maxilar. As causas mais frequentes de HPP persistente são a presença de doença multiglandular ou de paratiroide anômala ectópica ou ortotópica não identificada previamente. É recomendável que a localização imagiológica preceda a reintervenção cirúrgica. A janela aortopulmonar é uma localização ectópica rara, sendo o ${ }^{99 \mathrm{~m} T c-}$

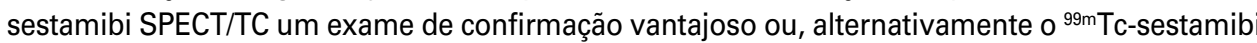
seguido de TC ou RM torácica. A paratiroidectomia pode ser efetuada por meio de esternotomia mediana, toracotomia ou toracoscopia videoassistida. Descrevemos um caso de HPP persistente atribuível à presença de uma glândula paratiroide ectópica localizada à janela aortopulmonar. 0 diagnóstico de HPP foi estabelecido na sequência da investigação requisitada para esclarecimento etiológico da nefrolitíase recidivante constatada nessa doente. Foi submetida à paratiroidectomia subtotal; não obstante, o HPP persistiu. Excluíram-se síndromes genéticas que pudessem justificar esse quadro clínico. Os exames imagiológicos disponíveis (à época) revelaram-se infrutíferos na detecção de paratiroides anômalas; adicionalmente, a doente recusou exploração cirúrgica. Posteriormente, a doente foi submetida a ${ }^{99 m}$ Tc-sestamibi SPECT/TC, que revelou a presença de uma paratiroide na janela aortopulmonar. Arq Bras Endocrinol Metab. 2012;56(6):393-403
Endocrinology, Diabetes and Metabolism Department, Coimbra's University Hospital, Coimbra, Portugal

2 Nuclear Medicine Department, Coimbra's University Hospital, Coimbra, Portugal

Correspondence to:

Sofia Gouveia

Serviço de Endocrinologia,

Diabetes e Metabolismo

Hospitais da Universidade de

Coimbra, E.P.E.

Praceta Prof. Mota Pinto

3000-075 - Coimbra, Portugal

sofiamgouveia@gmail.com

Received on Dec/5/2011 Accepted on Apr/19/2012 


\section{INTRODUCTION}

\section{Characterization and etiology}

$\mathrm{P}$ rimary hyperparathyroidism (PHPT), the third most common endocrinopathy, mainly affects women aged between 50 and 60 years old. It results from intrinsic hyperfunction of one or more of the parathyroid glands (1).

Each normal gland measures about $6 \times 4 \times 2 \mathrm{~mm}$ and weights $25-50 \mathrm{mg}$. Patients usually have four glands, but the number can range from two to eight. Supernumerary glands commonly have some thymic tissue associated, suggesting they derived from an inferior parathyroid gland that underwent division during embryogenesis (2-4).

According to the histopathological characteristics and the number of glands involved, PHPT might be classified as being caused by a single adenoma (75\%$85 \%$ of the cases), hyperplasia ( $10 \%-20 \%)$, multiple adenomas (4\%-5\%) or carcinoma (1\%) (1-3,5-7).

PHPT may be sporadic or familial. Familial PHPT is generally associated with hypercalcemia detected before the age of twenty, positive family history, multiple endocrinopathies, multiglandular parathyroid disease (hyperplasia, multiple adenomas) or carcinoma. It affects both genders equally, and has a high recurrence rate. Genetic syndromes causing PHPT include multiple endocrine neoplasia (MEN type 1 or $2 \mathrm{~A}$ ), familial benign hypocalciuric hypercalcemia $(\mathrm{FBHH})$, and hyperparathyroidism jaw-tumor syndrome $(8,9)$.

Patients with MEN type 1 (MEN 1 gene) are prone to develop parathyroid, pancreatic, and pituitary tumors. By the age of 50 , hyperparathyroidism is present in $95 \%$ of the cases. MEN type $2 \mathrm{~A}$ (RET gene) is characterized by the presence of medullary thyroid carcinoma (95\% of the cases), pheochromocytoma (50\%), and hyperparathyroidism (30\%), the latter rarely being the first clinical manifestation of this syndrome (9).

Clinical presentation of hyperparathyroidism-jaw tumor syndrome (HRPT2 gene) comprises PHPT due to parathyroid carcinoma, hyperplasia or metachronous multiple adenomas ( $90 \%$ of the cases), mandible/maxilla ossifying fibromas and renal cysts, hamartomas, or Wilms' tumor $(7,9)$.

In what concerns to differential diagnosis, it is crucial to exclude familial benign hypocalciuric hypercalcemia (FBHH; CaSR gene), as this autosomal dominant benign condition requires only medical surveillance, making parathyroidectomy unnecessary and hazar- dous. The mutation in the calcium-sensing receptor (CaSR) determines a shift to the right in the calcemia set-point that inhibits PTH secretion. Therefore, these patients present mild hypercalcemia, normal or slightly increased PTH levels, and hypocalciuria (considerable renal reabsorption of calcium still remains after total parathyroidectomy). Other causes of hypercalcemia-hypocalciuria, such as thiazides or lithium use, should be ruled out. The calcium-to-creatinine clearance ratio $(\mathrm{CaCl} / \mathrm{CrCl})$ is widely used to distinguish $\mathrm{FBHH}$ from typical PHPT (in the former, daily calciuria will be less than $50 \mathrm{mg}$ and $\mathrm{CaCl} / \mathrm{CrCl}$ below 0.01$)(1,7,9)$.

\section{Clinical presentation and laboratorial diagnosis}

The great majority (70\%-85\%) of PHPT patients is asymptomatic. Therefore, diagnosis is determined when hypercalcemia revealed in routine blood tests triggers further investigation. Symptomatic patients may present nephrolithiasis, nephrogenic diabetes insipidus, bone pain, pathologic fractures, acute pancreatitis, constipation, nausea, vomiting, anorexia, dyspepsia, muscle weakness, hypertonia, anxiety, irritability, cognitive and concentration impairment, memory loss, depression, psychosis, neurosis, ataxia, coma, hypertension, arrhythmia, coronary artery disease, chondrocalcinosis, and pseudogout $(1,2,6,7,10,11)$.

From a laboratorial point of view, patients with PHPT exhibit hypercalcemia (normocalcemia, in some cases), normal to high levels of PTH (even normal levels are inappropriate, considering the coexistent hypercalcemia), hypophosphatemia, decrease in 25-hydroxyvitamin $\mathrm{D}$, and increase in 1, 25-dihydroxyvitamin D levels $(1,5,7,8)$.

If the patient presents persistent normocalcemia and elevation of PTH, causes of secondary hyperparathyroidism (chronic kidney disease, vitamin D insufficiency, pseudohypoparathyroidism type $1 \mathrm{~b}$, celiac disease, renal hypercalciuria, iatrogenesis - bisphosphonates, phosphorus, furosemide, anticonvulsants) should be excluded before diagnosis of normocalcemic PHPT is assumed. Sometimes, PHPT and vitamin D insufficiency may coexist, making the patient normocalcemic. However, as soon as vitamin D levels are restored, hypercalcemia will be revealed $(8,9,11)$.

In cases of hypercalcemia associated with normal levels of PTH, other diagnostic hypothesis besides PHPT should be considered, namely sarcoidosis, Paget's disease, milk drinker syndrome, hypervitaminosis A or $\mathrm{D}$, lithium or thiazide consumption (8). 


\section{Imaging localization}

In order to detect and locate abnormal parathyroid glands, some imaging tests, such as ultrasonography (US), computed axial tomography (CT), magnetic resonance imaging (MRI) and ${ }^{99 \mathrm{~m} T c}$-sestamibi scintigraphy are available. In order to reduce false-positive and false-negative results, PHPT should be confirmed biochemically prior to imaging studies $(1,3,6)$. False-positive results obtained with US, CT and MRI are mainly due to the presence of lymph or thyroid nodes $(6,10)$.

Regarding non-invasive imaging studies, ${ }^{99 \mathrm{~m} T c-s e s-}$ tamibi scintigraphy has the highest sensitivity (nearly $90 \%$ in single adenomas, but only $45 \%-60 \%$ if hyperplasia, and $30 \%-73 \%$ if double adenoma are implicated). PTH level, P-glycoprotein expression, size of the glands and predominant cell type (oxyphil content) are the major determinants for scintigraphy sensitivity. One advantage of this technique over US is its ability to detect ectopic mediastinal parathyroid glands. On the other hand, US is a cheaper, radiation-free procedure $(1,3,6,8)$.

False-negative results with ${ }^{99 \mathrm{~m}} \mathrm{Tc}$-sestamibi scintigraphy are more likely to occur in cases of multiglandular disease, high level of P-glycoprotein expression, small adenomas, and adenomas located at the carotid bifurcation (overlooked due to the expected submandibular activity). On the other hand, physiological asymmetric activity at the submandibular glands, misinterpreted as an ectopic submandibular parathyroid, might also be responsible for false-positive results $(2,3,6,12)$.

Another cause for false-positive results in scintigraphy would be the presence of thyroid nodules. If we are facing a patient with PHPT and previous history of thyroid nodules or goiter, the best non-invasive test would be the ${ }^{123} \mathrm{I}$ or ${ }^{99 \mathrm{~m}} \mathrm{Tc} /{ }^{99 \mathrm{~m}} \mathrm{Tc}$-sestamibi subtraction test. Therefore, if a focus of increased uptake on ${ }^{99 \mathrm{~m} T c-}$ -sestamibi has no translation at the same location on ${ }^{99 \mathrm{~m} T c}$ or ${ }^{123} \mathrm{I}$ scintigraphy (thyroid selective), it means that the focus correlates with a parathyroid abnormality. On the contrary, if both images obtained from the two scintigraphic exams overlap, showing changes in the same spot, then a thyroid nodule would be implicated $(3,10,12)$.

${ }^{99 \mathrm{~m}} \mathrm{Tc}$-sestamibi has a 30 -minute half-life in the thyroid, but the radiotracer is cleared more slowly from abnormal parathyroid glands. With dual-phase planar imaging, images are taken 5 minutes and 2 hours after tracer injection. Abnormal parathyroid glands are still visible in delayed images (in $60 \%$ of the cases), while the thyroid exhibits residual tracer activity, enhancing contrast, and making detection easier. Parathyroid adenoma and carcinoma are scintigraphically undistinguishable (3).

${ }^{99 \mathrm{~m}} \mathrm{Tc}$-sestamibi SPECT/CT is useful when seeking for small adenomas, ectopic glands and to provide further information to guide a surgical approach (especially if prior intervention and subsequent anatomic distortion has occurred). This exam provides functional and anatomic sequential data, obtained simultaneously with the same device, improving its accuracy to locate parathyroid adenomas, particularly if ectopic. As long as a parathyroid adenoma visualized on scintigraphic planar images is undistinguishable whether it is located at the aortopulmonary window or at the anterior mediastinum/thymus, ${ }^{99 \mathrm{~m} T c-s e s t a m i b i ~ S P E C T / C T ~ m i g h t ~}$ unmask the true site of ectopic parathyroid. As alternatives, CT or MRI could be used $(3,13,14)$.

CT and MRI both show great ability to detect ectopic parathyroid glands. CT presents some disadvantages over MRI, such as low definition on the thyroid area and risk for complications related to ionizing radiation and iodinated intravenous contrast (15).

\section{Treatment}

Parathyroidectomy is the only hypothesis for PHPT definitive cure. When carried out by an experienced surgeon (at least 10 parathyroid interventions every year), success rate is nearly $95 \%(1,8,16)$. Surgery is recommended for symptomatic patients, with renal or skeletal involvement $(1,11,17)$.

Data available about postoperative improvement of cardiovascular or neuropsychiatric symptoms, as well as on related mortality rate, are conflicting. Therefore, the mentioned clinical manifestations are not presently considered indications for surgery. Likewise, hypercalciuria is no longer considered recommendation for parathyroidectomy. In fact, calciuria is not a predictor, but only a cofactor for the development of kidney stones (together with urinary volume, $\mathrm{pH}$, oxalate, citrate, and uric acid concentration). Furthermore, calciuria depends on age, gender, race, calcium intake, vitamin D status, and glomerular filtration rate; consequently, a consensual absolute cut-off value is not feasible (11).

Asymptomatic patients who fulfill any of the following criteria should also undergo surgery: younger than 50 years-old; serum calcium maintained at no less 
than $1.0 \mathrm{mg} / \mathrm{dL}(0.25 \mathrm{mmol} / \mathrm{L})$ above the upper limit of the reference range; creatinine clearance (based on MDRD equation) below $60 \mathrm{~mL} / \mathrm{min}$; bone density T-score (on lumbar spine, total hip, femoral neck, or distal third radius) of -2.5 or less (in postmenopausal women/men aged 50 or older); or if medical surveillance is impracticable or if the patient him/herself does not desire it $(9,17)$.

According to a possible surgical approach, all four glands must be identified and compared. If any of the observed glands raises some uncertainty in relation to normality, a biopsy could be undertaken. If one or two adenomas are recognized, it/they should be excised $(1,2,5,7)$.

In cases of hyperplasia, the surgeon should first remove part of the most (macroscopically) regular gland, assess vascular viability of the $50 \mathrm{mg}$ remnant, and then excise the other 3 abnormal parathyroids (subtotal parathyroidectomy). If parathyroid hyperplasia is diagnosed on a context of suspected familial hyperparathyroidism, a total parathyroidectomy is advisable, with subsequent autotransplantation or cryopreservation and later reimplantation of some parathyroid tissue to the forearm (after excluding the hypothesis of carcinoma). Total parathyroidectomy and autotransplantation/reimplantation is associated with lower surgical risk, in cases of PHPT recurrence, making a new intervention necessary $(2,5,7,16)$.

When only 3 parathyroid glands are found in their regular location, the surgeon should carefully seek for the missing parathyroid at the possible ectopic locations reachable in a cervical approach: tracheoesophageal groove, thymus, ipsilateral thyroid, and upper cervical region. After assessing those regions, the surgeon could dissect the carotid sheath (starting at the carotid bifurcation) and the retroesophageal space, recurring to palpation and ultrasonography whenever possible $(2,5,10)$. Some authors recommend that a fifth ectopic parathyroid should also be searched if all four glands found at the cervical region were normal or hyperplasic (2).

One alternative surgical approach is to remove the presumptive abnormal parathyroid and perform intraoperative PTH (IOPTH) assay to ensure that the proper gland was excised $(1,6,8)$.

Success of minimally invasive parathyroidectomy (MIP) relies on the accuracy of pre-operative imaging studies and intraoperative techniques (such as IOPTH assay and hand-held gamma probe) to detect multiglandular disease. Advantages of this surgical option include better cosmetic outcome, as the incision is smaller, use of local or light general anesthesia, shorter operating time and hospital stay, lower hospital costs, better surgical conditions if reoperation is needed, preservation of normal parathyroid glands, decreased post-operative hypocalcemia, and/or risk of bilateral recurrent laryngeal nerve injury. However, adjuvant techniques as IOPTH increase the final cost of MIP (18-24).

MIP should be reserved for patients who meet some requirements, namely absence of previous neck surgery, single-gland disease and adenoma diameter smaller than 30 millimeters. It is not an advisable option for patients with negative or discordant imaging localization studies, known genetic syndromes, secondary or tertiary hyperparathyroidism, multiglandular disease, extra-cervical ectopy, parathyroid carcinoma, large goiter, or need for thyroidectomy $(18-23,25,26)$.

The criteria commonly applied to assess cure based on the evolution of IOPTH levels are Miami, Rome, and Vienna criterion. According to the Miami criterion, IOPTH is expected to decrease over $50 \%$ from the highest of either pre-operative baseline or pre-excision level when ten minutes have elapsed after gland removal. On the grounds of the Rome criterion, IOPTH 20 minutes post-excision should be within the reference range and/or less than $50 \%$ of the highest pre-excision level and/or at least $7.5 \mathrm{ng} / \mathrm{L}$ lower than IOPTH assay at 10 minutes post-excision. Based on the Vienna criteria, a decline in IOPTH levels of over $50 \%$ (from pre-operative baseline to 10 minutes post-excision) would predict surgical cure $(19,27)$.

Pre-excision level is obtained in a blood sample collected after gland mobilization and just prior to devascularization. It may be greater (if gland manipulation triggers a hormone spike) or lower (in case ischemia and subsequent gland necrosis occur) than pre-incision level. Blood should be obtained preferably from peripheral vessels rather than from jugular veins, in order to prevent detection of spuriously high PTH levels $(18,20)$.

When IOPTH cure levels are not achieved, search for additional hyperfunctional parathyroid tissue (hyperplasia or double adenoma often not detected in pre-operative imaging studies) should be performed, by means of conversion to bilateral neck exploration $(6,23)$.

False-negative results are reported when serial PTH levels do not fulfill the cure criteria, even though all abnormal parathyroid glands have been removed, and the patient remains eucalcemic for the following 6 
months. This error may lead to unnecessary expansion of surgical exploration for non-existent multiglandular disease, and consequently increase time spent, costs, and surgical morbidity. A slower decline in PTH levels, which occurs in case of chronic kidney disease, removal of large adenoma, parathyroid cyst rupture, longer PTH half-lives (that could vary from 2 to 5 minutes), and employment of assays unable to discriminate between biologically active PTH (1-84), and amino-terminally truncated PTH fragments (inactive metabolites, with longer half-lives) could account for such results. It can also be ascribable to undetected spikes in relation to manipulation of abnormal parathyroid glands (10 minute post-excision level might show a $50 \%$ reduction compared with pre-excision results, but it is still higher than half the pre-operative baseline value) $(8,18-21,27)$.

However, some authors argue that pre-excision samples are dispensable, as long as PTH spike set off by surgical manipulation does not interfere with its short half-life. Therefore, PTH is expected to be within the reference range 10 to 15 minutes after gland exeresis, regardless spike magnitude $(20)$.

False-positive results are described when, despite cure criteria have been met, PHPT persists. Patients with multiglandular disease may present false-positive results, considering that $\mathrm{PTH}$ levels decline suddenly after parathyroid removal, but will eventually rise again, as soon as other abnormal gland(s) recover from previous suppression $(18,22,27)$.

In the Irvin and cols. series, MIP with IOPTH assay $(\mathrm{n}=42 \mathrm{l})$ presented lower operative failure $(3 \mathrm{vs} .6 \%$; $\mathrm{p}=0.02)$ and multiglandular disease rate (3 vs. $10 \% ; \mathrm{p}$ $<0.001)$ compared with bilateral neck exploration (n $=340)(18)$.

Lew and cols. published a series of 225 patients with PHPT whose initial surgical procedure was MIP with IOPTH assay. Each patient was previously submitted to a ${ }^{99 \mathrm{~m}} \mathrm{Tc}$-sestamibi and US. The group with concordant localizing imaging studies $(\mathrm{n}=140)$ had a higher rate of surgical success (99 vs. 93\%; p < 0.01) and lower multiglandular disease frequency $(2 v s .11 \% ; \mathrm{p}=0.01)$ than the group with discordant results $(\mathrm{n}=85)$. IOP$\mathrm{TH}$ prevented unnecessary bilateral exploration in $66 \%$ of the discordant imaging results group and predicted properly surgical failure in all incorrect imaging studies from concordant imaging results group, enabling the surgeon to proceed exploration. Overall, IOPTH technique contributed to a $97 \%$ success rate and a $99 \%$ accuracy rate ( 2 false-positive and 1 false negative were recorded) (25).

Likewise, Smith and cols. have compared 3 groups of patients who underwent MIP with IOPTH assay. All patients had previous ${ }^{99 \mathrm{~m}} \mathrm{Tc}$-sestamibi and US. Patients who presented concordant and localizing studies $(\mathrm{n}=$ 209 ) had a 97\% MIP success rate. IOPTH assay had a minimal impact in preventing failure (3\%) in this group and was, consequently, considered unlikely beneficial in this kind of patients. On the contrary, in patients with discordant imaging studies $(\mathrm{n}=143)$, MIP success rate was $80 \%$ and IOPTH boosted final surgical success rate (MIP + conversion to bilateral exploration) to $97 \%$. MIP success rate in patients with concordant non-localizing imaging studies ( $\mathrm{n}=76$; predominantly multiglandular disease) was $41 \%(21)$.

Barczynski and cols. also presented data showing that use of IOPTH assay is a useful method to support the surgeon's decision for further neck exploration. It led to conversion to bilateral exploration in $3.8 \% \mathrm{pa}$ tients with concordant studies, and in $18.9 \%$ patients with only one positive imaging study $(\mathrm{p}=0.007)$. Even so, these authors recommend IOPTH in all patients submitted to MIP, whether imaging studies are concordant or not (22).

Patients undergoing unilateral neck exploration without IOPTH assay had, compared with MIP with IOPTH assay, lower cure rates $(91.9 \%$ vs. $99.1 \%$; $\mathrm{p}=$ $0.01)$, higher persistent $(8.1$ vs. $0.9 \% ; \mathrm{p}=0.01)$ and recurrent PHPT rates $(4.8 \%$ vs. $0.9 \% ; \mathrm{p}=0.07)$. $\mathrm{Pa}-$ tients from both groups had at least one positive pre-operative imaging study, but length of follow-up was significantly shorter in the MIP group. IOPTH improved cure rate from $91.3 \%$ to $99.1 \%$ in MIP group. One false-negative was recorded, but no false-positive (22).

Chen and cols. published similar results. Patients subjected to unilateral $(n=121)$ or bilateral $(n=36)$ cervical exploration without IOPTH assay had, compared with those who underwent MIP with IOPTH $(\mathrm{n}=188)$, a lower cure rate $(90$ vs. $100 \% ; \mathrm{p}<0.001)$. In the MIP group, IOPTH assay enabled cure in $10 \%$ more patients, who otherwise would require a second intervention (26).

Jacobson and cols. claim that patients with a single-gland disease, unequivocally identified on ${ }^{123} \mathrm{I} /{ }^{99 \mathrm{~m}} \mathrm{Tc}$ -sestamibi SPECT/CT, can be successfully treated by unilateral cervical approach without IOPTH. In fact, their series (100 patients who had a single adenoma at ${ }^{123} \mathrm{I} /{ }^{99 \mathrm{~m} T c}$-sestamibi SPECT/CT and underwent focu- 
sed cervical exploration without IOPTH assay) had a $97 \%$ success rate. With such tight inclusion criteria, the selected population represented only $9 \%$ of all cervical explorations for PHPT performed at their institution during the period of study (24).

Patients may develop hungry bone syndrome post-parathyroidectomy if quick bone remineralization with calcium and phosphate uptake occurs. Following surgery, PTH levels suddenly fall, preventing osteoclastic and enabling osteoblastic activity to proceed. Therefore, a state of severe hypocalcemia might ensue, unless the remaining parathyroid tissue increases PTH secretion to restore normocalcemia. Older patients, with large adenomas, osteitis fibrosa cystica, secondary hyperparathyroidism, and high preoperative serum calcium, PTH and alkaline phosphatase levels are at risk for hungry bone syndrome $(7,28)$.

When a patient presents hypocalcemia after parathyroidectomy, differential diagnosis between hungry bone syndrome and surgical hypoparathyroidism is needed. In hungry bone syndrome, the patient has hypophosphatemia and PTH elevation. On the other hand, patients with surgical hypoparathyroidism present low PTH and subsequent high phosphate (7).

There are several medical treatment options for those patients who were not submitted to a surgical procedure, namely bisphosphonates, hormone replacement therapy, selective estrogen receptor modulators, or calcimimetic agents. These patients have to continue to be regularly evaluated (serum calcium and creatinine annually, dual energy X-ray absorptiometry every 1-2 years), in order to assure early detection of clinical deterioration that would make parathyroidectomy indicated for them. If required, vitamin D supplements should be prescribed aiming at achieving and maintaining 25-hydroxivitamin $\mathrm{D}$ serum level greater than 20 $\mathrm{ng} / \mathrm{dL}(50 \mathrm{nmol} / \mathrm{L})(1,9,11,17)$.

\section{Persistent PHPT}

Persistent PHPT refers to a sustained hypercalcemia state detected within the first six months following parathyroidectomy. On the other hand, the designation recurrent $P H P T$ is applicable when the patient has been normocalcemic for at least six months after surgery, and then hypercalcemia reappears (16).

First of all, it is critical to confirm that PHPT diagnosis is accurate; other diagnostic hypothesis should be reviewed and eliminated $(2,8,16)$.
The most common cause of persistent PHPT is the presence of an ectopic gland that was not identified in the first intervention. Other causes include a previously unnoticed multiglandular disease (multiple adenomas or hyperplasia) or a missed abnormal orthotopic gland $(5,10,29)$.

Recurrent PHPT is ascribable to an ectopic abnormal gland that was not detected earlier; occurrence of parathyromatosis (seeding of parathyroid cells along cervical region during surgical intervention); regrowth of a parathyroid which accidentally underwent only partial resection, or of the remnant left in a context of hyperplasia. Less frequent causes include metachronous double adenoma (patients with previous cervical irradiation are at particular risk of presenting two adenomas that arose from different genetic events, at different moments); or parathyroid carcinoma $(5,8,10)$.

After a first unsuccessful surgery, induced fibrosis and distortion of normal tissue planes may jeopardize the outcome of a new intervention. Preoperative imaging studies are indispensable to guide a reoperation, and to detect ectopic parathyroid glands. The combination of ultrasonography and ${ }^{123} \mathrm{I}$ or ${ }^{99 \mathrm{~m}} \mathrm{Tc} /{ }^{99} \mathrm{~m} \mathrm{Tc}-$ -sestamibi subtraction test is probably a cost-effective strategy, and shall be the first option in preoperative study of persistent/recurrent PHPT $(3,8,10)$.

However, if non-invasive studies are not able to identify an abnormal gland, or if disagreeing results are obtained, then the patient should be submitted to selective angiography or selective venous sampling for PTH. Both techniques are invasive (requiring extended exposure to contrast and radiation), expensive and not routinely performed, demanding supervision by an experienced radiologist. If non-invasive studies detect a suspicious lesion (not clearly identified as a parathyroid), fine needle aspiration with cytological examination and PTH assay of aspirate are suitable to confirm diagnosis $(6,10,15)$.

\section{Ectopic parathyroid glands}

The incidence of ectopic parathyroid glands in patients with PHPT ranges from $9 \%$ to $20 \%(2,5,12,29)$. Superior parathyroid glands (together with the lateral thyroid) arise from the fourth pharyngeal pouch. Lateral thyroid will later merge with the lateral wing of the median thyroid, and superior parathyroid glands are supposed to be nearby, in the dorsum of the upper pole of thyroid or posteriorly to the cricothyroid region. Or- 
thotopic inferior parathyroid glands are presumed to be found in anterior or posterolateral lower pole of the thyroid $(2-5,10,12)$.

The ectopic parathyroid glands are more often derived from inferior glands. The inferior glands have a longer migration path, granting them a higher probability of being ectopic, from the mandible angle (quite rarely from the nasal septum) to the pericardium. In fact, inferior glands (which arise, together with the thymus, from the third pharyngeal pouch) usually have some thymic tissue associated, what might be useful when clarifying the presumptive origin of ectopic glands $(2,4,5,10,12,14,29,30)$.

Most common locations for ectopic superior glands are the tracheoesophageal groove, retroesophageal spa$\mathrm{ce}$, posterosuperior mediastinum, intrathyroidal (parathyroid gland embedded in thyroid tissue, without capsule), carotid sheath, and paraesophageal space. Considering inferior glands, the ectopic sites would be intrathymic, anterosuperior mediastinum, intrathyroidal, thyrothymic ligament, and submandibular area. Rarely, ectopic parathyroid glands may be located at the aortopulmonary window, pericardium, hypopharynx (pyriform sinus), nasopharynx, vagus nerve sheath (arising from the fourth pharyngeal arch, near the third and fourth pharyngeal pouches) or posterior cervical triangle $(2,5,10,12,13,29,30)$.

There are two theories, not mutually exclusive, that justify the occurrence of ectopic glands. One states that an abnormal gland orthotopically located (adenoma, hyperplasia, carcinoma) becomes larger and heavier and, as the gland is not steadily fixed, it could eventually be vertically displaced by gravity. This theory may account for the main locations of ectopic superior glands. Another theory (mainly related to ectopic inferior glands) claims that an abnormal event disturbing parathyroid migration during embryogenesis would interfere with its final location $(2,4,5,12)$.

Most ectopic parathyroid glands located at the aortopulmonary window (APW) are found to be supernumerary. When the fourth parathyroid is at the APW, it usually proceeds from a superior gland. During embryogenesis, the superior parathyroid gland has close contact, for a certain period of time, with the recurrent laryngeal nerve, the aortic arch, and the sixth branchial artery (origin of the future right pulmonary artery). In cases of early individualization of superior parathyroid glands (before the mentioned structures became completely distinct), some parathyroid cells might remain on what will become the APW. When the inferior parathyroid gland individualizes from the third pharyngeal pouch, some parathyroid cells may persist connected to the adjacent pericardium (if so, the abnormal parathyroid at APW will present some thymic tissue associated to it) $(13,29,30)$.

An ectopic parathyroid gland located at the APW may be excised through median sternotomy, left or right thoracotomy or video-assisted thoracoscopy. Some structures could be injured by proximity during intervention, namely the vagus, recurrent laryngeal and phrenic nerve, aorta, and pulmonary artery and veins $(13,14)$.

Some authors presented data showing that patients with PHPT related with ectopic glands have higher levels of serum calcium, larger adenomas and, more frequently, severe bone disease associated with it. As there are few cases, these conclusions have to be considered with caution. Ectopic glands are often related with false-negative imaging results, and unsuccessful or complicated surgical (re)interventions $(5,12,14)$.

\section{CASE REPORT}

A 35 years-old Caucasian female with a background history of acute renal colic, pyelonephritis, and urosepsis, was referred to Urology Department, and underwent a successful extracorporeal lithotripsy. However, the disease has recurred two years later, and the subsequent etiologic investigation revealed high levels of PTH (383; RR:10-65 pg/mL), hypercalcemia (12.2; RR:8.1-10.4 mg/dL) and hypophosphatemia (2.2; RR:3-5 mg/dL). Her family history was negative for hypercalcemia, osteoporosis, nephrolithiasis, or endocrinopathies.

A cervical ultrasound was unable to detect any parathyroid gland, but the cervical MRI disclosed the presence of an image suggesting a hypertrophic parathyroid in a setting of a hypertrophic heterogeneous right thyroid lobe.

Considering the diagnosis of primary hyperparathyroidism and the location of a hypothetical abnormal parathyroid gland, the patient underwent surgical cervical exploration, with a subtotal parathyroidectomy and right partial hemithyroidectomy as final outcome. Three suspicious nodes on the left side, resembling parathyroid glands, were removed. As no nodes were found on the right cervical region, it was assumed that parathyroid glands were intrathyroidal and therefore, 
the right thyroid lobe was partially removed. Further surgical exploration during this intervention was not attempted. Intraoperative PTH assay was not a standardized procedure at that time.

The histological report confirmed thyroid nodular hyperplasia, normal upper and lower left parathyroid glands, and a hyperplasic left parathyroid gland (nodule located near the left carotid).

As the patient maintained high levels of serum calcium $(11.5 \mathrm{mg} / \mathrm{dL})$ and PTH $(385 \mathrm{pg} / \mathrm{mL})$ a month later, she was referred to Endocrinology Department for further investigation. The patient was admitted to Endocrinology ward nine months after the surgical intervention. At the time of admission, PTH was $328 \mathrm{pg} /$ $\mathrm{mL}$ and serum calcium $11 \mathrm{mg} / \mathrm{dL}$. Our main purpose was to fully characterize clinical involvement, and to evaluate if familial PHPT and/or an ectopic abnormal gland could account for this case of persistent PHPT.

In order to achieve our first aim, we requested several procedures. A dual energy X-ray absorptiometry revealed highly reduced bone mineral density (BMD) at the lumbar spine (T-4.53 SD), hip (T-3.13SD), and distal third radius (T-4.63 SD), implying osteoporosis with a high risk of fracture. Skeleton X-ray showed a typical salt-and-pepper skull, as well as diffuse osteopenia. Renal ultrasound exhibited old signs of pyelonephritis without obvious evidence of nephrolithiasis.

Aiming at determining the etiology of persistent PHPT, we assessed daily calciuria (170.8 mg), calcium-to-creatinine ratio $(0.01)$, pituitary function, insulin, $\mathrm{C}$ peptide, calcitonin, and urinary metanephrine levels, all of which were adequate. Brain CT (the patient refused MRI) displayed a normal pituitary gland. A cervico-thoraco-abdominal CT did not show any abnormality on what concerns to pancreas, adrenals, or the presence of an ectopic gland. Technetium-99m scintigraphy was not available at that time in our Hospital.

The patient was kept under periodic medical surveillance for the following five years. She maintained high levels of PTH (ranging from 400 to $758 \mathrm{pg} / \mathrm{mL}$ ), calcemia (11.0-11.8 mg/dL), hypophosphatemia (1.7$2.0 \mathrm{mg} / \mathrm{dL})$, and calciuria $(350-832 \mathrm{mg} / 24$ hours $)$. Worsening of osteoporosis stage and nephrolithiasis recurrence were registered. Additional cervical ultrasound/CT performed were unable to identify a parathyroid gland. The patient refused to undergo cervical MRI or surgical exploration.

The patient started bisphosphonates therapy on the fifth year of follow-up. A cervical ultrasound disclosed a $2.2 \times 2 \mathrm{~cm}$ calcified solid lesion located posteriorly to sternum. Unfortunately, she quitted the Endocrinology appointments before further evaluation, even though she kept her follow-up on the Surgical Department. A technetium-99m scintigraphy exhibited discreet tracer activity at the lower pole of the left thyroid lobe (on delayed images) and at the middle mediastinum. The patient repeatedly postponed surgical intervention and eventually dropped out of her appointments in the Surgical department.

Ten years later, she was redirected to our Department for re-evaluation. Blood tests were performed three months after interrupting treatment with bisphosphonates and vitamin $\mathrm{D}$, whose results are exhibited on table 1 .

Table 1. Laboratory data

\begin{tabular}{lcc}
\hline & Result & Reference range \\
\hline PTH & 1449 & $9-72 \mathrm{pg} / \mathrm{mL}$ \\
25-hydroxyvitamin D & 19 & $10-68 \mathrm{ng} / \mathrm{mL}$ \\
Serum calcium & 12.5 & $8.8-10.6 \mathrm{mg} / \mathrm{dL}$ \\
Serum phosphorus & 2.1 & $2.5-4.5 \mathrm{mg} / \mathrm{dL}$ \\
Alkaline phosphatase & 180 & $30-120 \mathrm{U} / \mathrm{L}$ \\
Creatinine & 0.39 & $0.55-1.02 \mathrm{mg} / \mathrm{dL}$ \\
Albumin & 4.4 & $3.5-5.2 \mathrm{~g} / \mathrm{dL}$ \\
Total protein & 7.1 & $6.6-8.3 \mathrm{~g} / \mathrm{dL}$ \\
FSH & 36 & P.M. $>34 \mathrm{mUI} / \mathrm{mL}$ \\
LH & 33 & P.M. $>25 \mathrm{mUI} / \mathrm{mL}$ \\
Estradiol & $<10$ & P.M. $<14 \mathrm{pg} / \mathrm{mL}$ \\
Progesterone & $<0.2$ & P.M. $<0.7 \mathrm{ng} / \mathrm{mL}$ \\
Prolactin 0'/15'/30' & $9.6 / 8.6 / 7.7$ & $<20 \mathrm{ng} / \mathrm{mL}$ \\
GH 0'/15'/30' & $0.1 / 0.4 / 0.37$ & $<1 \mu \mathrm{g} / \mathrm{L}$ \\
IGF-I & 176 & $81-225 \mathrm{ng} / \mathrm{mL}$ \\
ACTH & 9.2 & $9-52 \mathrm{pg} / \mathrm{mL}$ \\
Cortisol & 17 & $5-25 \mu \mathrm{g} / \mathrm{dL}$ \\
TSH & 2.0 & $0.4-4.0 \mu \mathrm{UI} / \mathrm{mL}$ \\
Free T3 & 3.3 & $1.8-4.2 \mathrm{pg} / \mathrm{mL}$ \\
Free T4 & 1.1 & $0.8-1.9 \mathrm{ng} / \mathrm{dL}$ \\
Insulin & 3.3 & $<30 \mu \mathrm{UI} / \mathrm{mL}$ \\
C peptide & $1.0-7.6 \mathrm{ng} / \mathrm{mL}$ \\
Gastrin & $<90 \mathrm{pg} / \mathrm{mL}$ \\
Vasoactive intestinal peptide & $<170 \mathrm{pg} / \mathrm{mL}$ \\
\hline & & \\
\hline
\end{tabular}

To assess renal and bone involvement, the patient was submitted to renal ultrasound (that has shown the presence of multiple kidney stones) and to a dual energy X-ray absorptiometry (which has shown a high risk 
of fracture, with a low BMD at lumbar spine (T-4.3 SD) and hip (T-2.9 SD), although slightly better than the previous evaluation.

Cervical ultrasound revealed a heterogeneous thyroid, with multiple hypoechogenic areas, the largest ones of $5 \mathrm{~mm}$ in length.

As long as the prior imaging studies could not identify any parathyroid gland, we recommended ${ }^{99} \mathrm{~m}$ Tc-sestamibi scintigraphy. Tracer activity was then detected at the thorax. Therefore, SPECT/CT was employed in order to state the exact site of the possible ectopic gland, which was located at the aortopulmonary window (Figures 1 and 2).

To determine the size and anatomic relationships of the ectopic parathyroid gland (for guidance during surgery), we performed a cervico-thoracic CT. A $2.5 \mathrm{~cm}$ nodule located at the aortopulmonary window, with enhancement after contrast administration, was visualized. Some calcified infracentimetric mediastinal lymph nodes were also detected (Figures 3 and 4).

She underwent a thoracotomy through the fifth left intercostal space: the parathyroid was confined to a space between trachea, aortic arch and left pulmonary artery. Its exeresis damaged vascular and nervous structures, which has resulted on dysphonia. The removed gland weighted $1 \mathrm{~g}$, measured $3.5 \mathrm{~cm}$ and was described as hyperplasic on the histology report. The patient was discharged on calcium (3 g i.d.) and vitamin D $(0.75 \mu$ g i.d. $)$ replacement therapy.

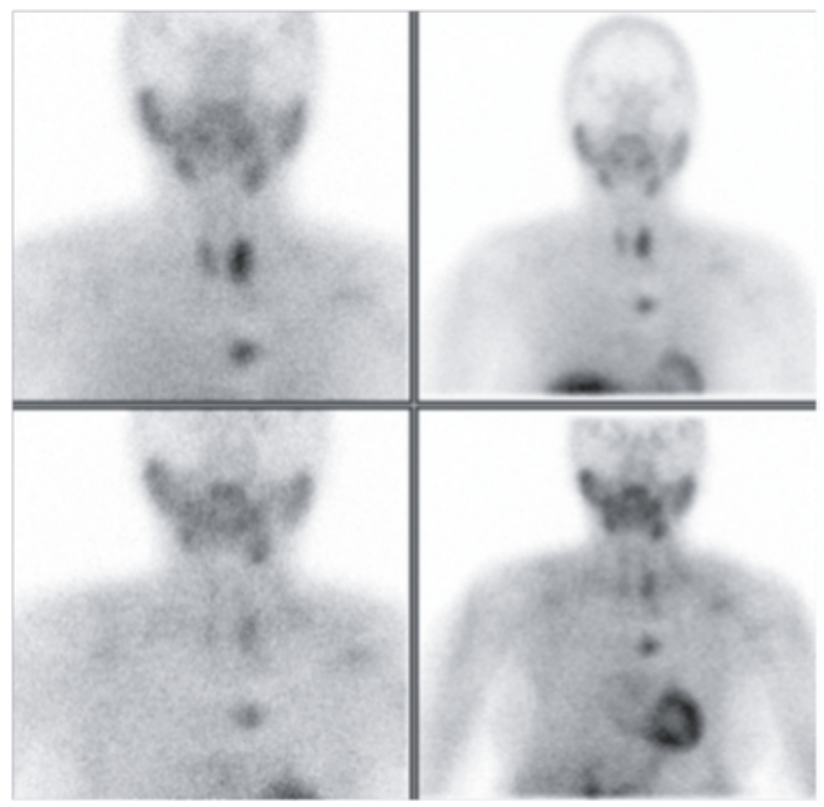

Figure 1. Anterior planar scintigraphic images show the presence of an ectopic parathyroid gland within the mediastinum.

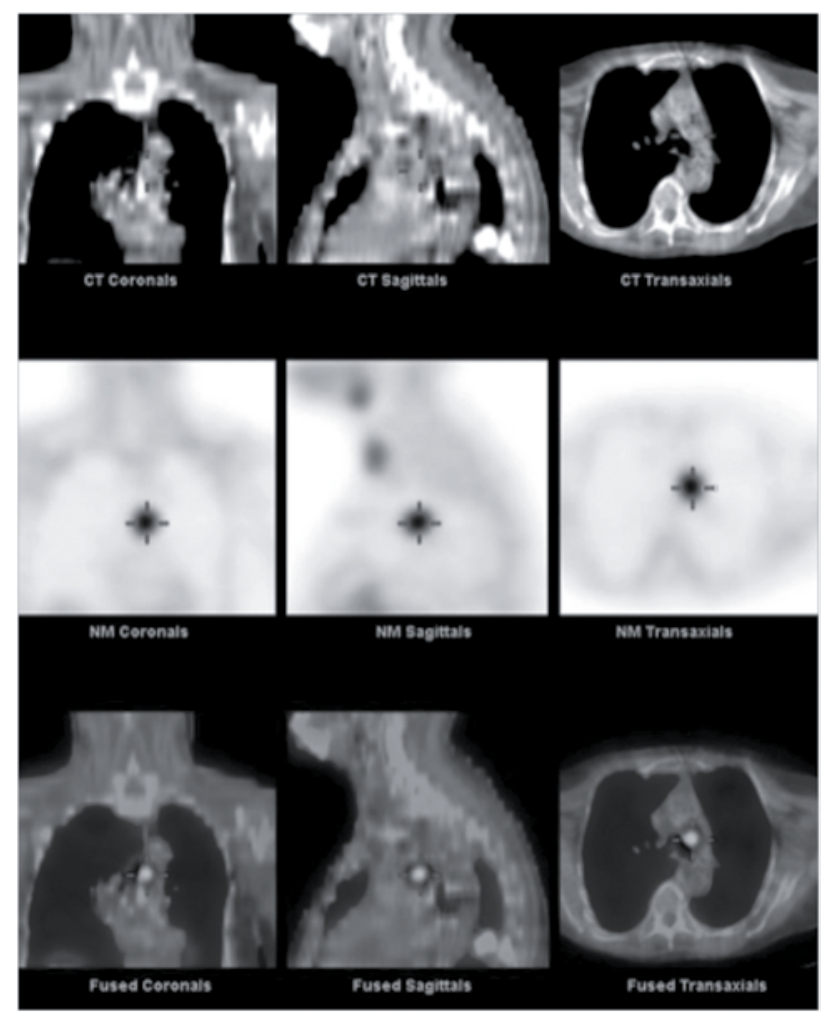

Figure 2. Top row-coronal, sagittal and axial CT images.

Middle row-coronal, sagittal and axial technetium-99m sestamibi SPECT images.

Bottom row-coronal, sagittal and axial fused technetium-99m sestamibi SPECT/CT images have identified the presence of an ectopic parathyroid gland located at the aortopulmonary window.
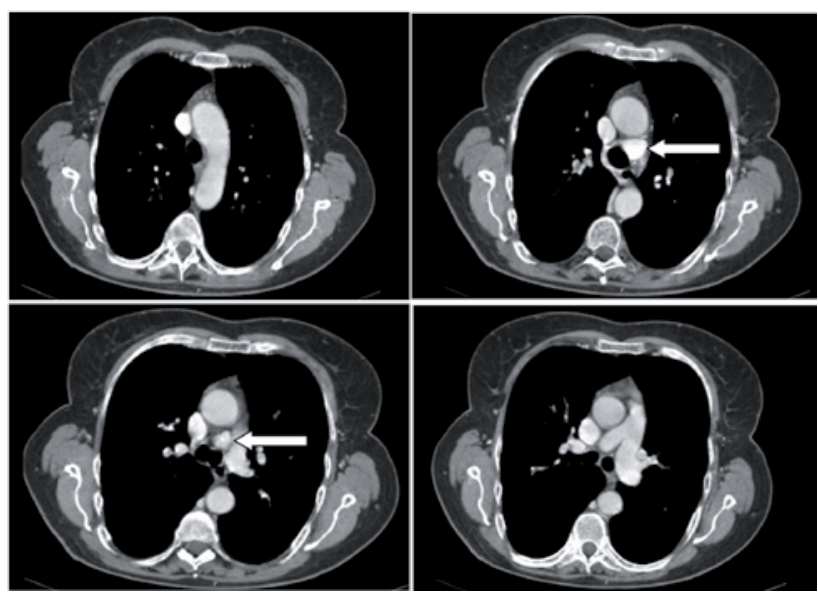

Figure 3. Top left-upper axial CT image showing the aortic arch just above the ectopic gland.

Top right and bottom left-axial CT images with arrows pointing out the ectopic gland at the aortopulmonary window.

Bottom right-lower axial CT image showing the pulmonary artery just below the ectopic gland. 


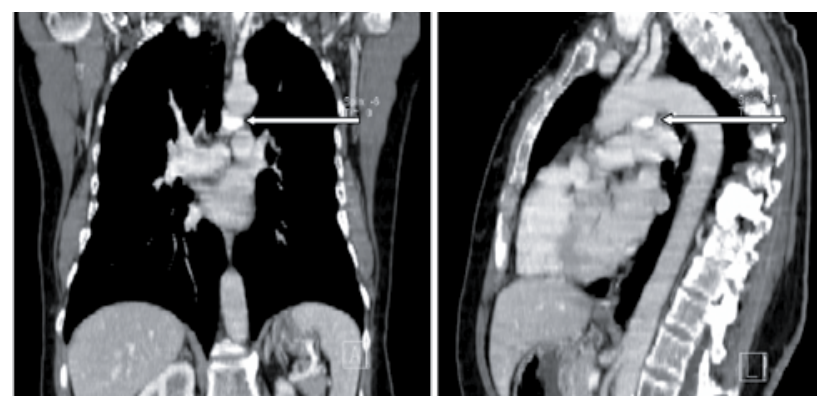

Figure 4. Left-coronal CT image. Right-sagittal CT image. The arrows show the exact location of the ectopic gland.

Two months post-surgery, she presents serum calcium of 9.8 (RR:8.8-10.6 mg/dL), phosphorus of 3.9 (RR:2.5-4.5 mg/dL) and PTH of 115 (RR:9-72 pg/ $\mathrm{mL})$. She is currently taking $\mathrm{l} \mathrm{g}$ of calcium carbonate and $0.25 \mu \mathrm{g}$ of vitamin $\mathrm{D}$ daily.

\section{DISCUSSION}

In patients with persistent PHPT, it is indispensable to carefully investigate the occurrence of hereditary syndromes and missed abnormal ectopic or orthotopic glands. In this report, we describe a case of symptomatic persistent PHPT.

In this case, the hypothesis of a familial PHPT seemed unlikely, given that we could not detect hypocalciuria; endocrine involvement, except for parathyroid disease; or familial history of hypercalcemia, parathyroid disease, jaw tumor, or renal cysts.

On the other hand, the circumstance that only three parathyroids were detected at cervical region strengthened hypothesis of ectopic glands. All three parathyroid glands identified were on the left side of the cervical region. Therefore, we can infer that one of those glands was supernumerary, and that at least two parathyroid glands (that should have been located at the right side) were missing. A thorough cervical exploration (during first surgery) should have been done.

The two normal parathyroid glands should not have been removed during the first surgical intervention. As a result of this strategy, the future risk of hypoparathyroidism (related to the subsequent exeresis of the remnant abnormal ectopic glands) was increased. The unavailability of intraoperative PTH assay, as well as of ${ }^{99 \mathrm{~m} T c-s e s t a m i b i}$ scintigraphy, has compromised an early diagnosis of persistent PHPT/unsuccessful surgery, and an accurate location of the abnormal gland. The initial cervico-thoraco-abdominal CT was pointless in what concerns to detection of ectopic glands.
As proven by this case, if the ectopic gland seems to be located at the mediastinum on scintigraphic planar images, it is advisable to complete the study with an anatomic imaging technique (SPECT/CT; CT; MRI) to prevent unnecessary repeated surgical interventions performed until the aortopulmonary window hypothesis is considered.

Further decrease of BMD was prevented by bisphosphonates therapy, which was kept for over ten years.

Presently, the patient PTH levels are still detectable (in fact, slightly elevated), even after exeresis of four parathyroid glands. A fifth viable parathyroid gland (at least) could justify this setting, despite the fact that all the imaging studies already performed could not detect it. Another possible explanation is the presence of parathyromatosis (if the fifth parathyroid gland experienced direct injury or ischemia during the first surgical intervention).

Disclosure: no potential conflict of interest relevant to this article was reported.

\section{REFERENCES}

1. Fraser WD. Hyperparathyroidism. Lancet. 2009;374(9684):145-58.

2. Kaplan EL, Yashiro T, Salti G. Primary hyperparathyroidism in the 1990s: choice of surgical procedures for this disease. Ann Surg. 1992;215(4):300-17.

3. Smith JR, Oates ME. Radionuclide imaging of the parathyroid glands: patterns, pearls, and pitfalls. Radiographics. 2004;24(4):1101-15.

4. Wang CA. The anatomic basis of parathyroid surgery. Ann Surg. 1976;183(3):271-5.

5. Mendoza V, Ramírez C, Espinoza AE, González GA, Peña JF, Ramírez ME, et al. Characteristics of ectopic parathyroid glands in 145 cases of primary hyperparathyroidism. Endocr Pract. 2010;16(6):977-81.

6. Udelsman R, Pasieka JL, Sturgeon C, Young JE, Clark OH. Surgery for asymptomatic primary hyperparathyroidism: proceedings of the Third International Workshop. J Clin Endocrinol Metab. 2009;94(2):366-72.

7. Shoback D, Sellmeyer D, Bikle DD. Metabolic bone disease. In: Gardner DG, Shoback D. Greenspan's Basic \& Clinical Endocrinology. 8th edition. McGraw-Hill companies; 2007. p. 281-345.

8. Blanchard C, Mirallié E, Mathonnet M. Sporadic primary hyperparathyroidism. J Visc Surg. 2010;147(5):e285-95.

9. Eastell R, Arnold A, Brandi ML, Brown EM, D'Amour P, Hanley DA, et al. Diagnosis of asymptomatic primary hyperparathyroidism: proceedings of the Third International Workshop. J Clin Endocrinol Metab. 2009;94(2):340-50.

10. Jaskowiak N, Norton JA, Alexander HR, Doppman JL, ShawkerT, Skarulis $\mathrm{M}$, et al. A prospective trial evaluating a standard approach to reoperation for missed parathyroid adenoma. Ann Surg. 1996;224(3):308-20; discussion 320-2.

11. Silverberg SJ, Lewiecki EM, Mosekilde L, Peacock M, Rubin MR. Presentation of asymptomatic primary hyperparathyroidism: 
proceedings of the Third International Workshop. J Clin Endocrinol Metab. 2009;94(2):351-65.

12. Phitayakorn R, McHenry CR. Incidence and location of ectopic abnormal parathyroid glands. Am J Surg. 2006;191(3):418-22; discussion 422-3.

13. Doppman JL, Skarulis MC, Chen CC, Chang R, Pass HI, Fraker $\mathrm{DL}$, et al. Parathyroid adenomas in the aortopulmonary window. Radiology. 1996;201(2):456-62.

14. Levine DS, Belzberg AS, Wiseman SM. Hybrid SPECT/CT imaging for primary hyperparathyroidism: case reports and pictorial review. Clin Nucl Med. 2009;34(11):779-84.

15. Peeler BB, Martin WH, Sandler MP, Goldstein RE. Sestamibi parathyroid scanning and preoperative localization studies for patients with recurrent/persistent hyperparathyroidism or significant comorbid conditions: development of an optimal localization strategy. Am Surg. 1997;63(1):37-46.

16. Shen $W$, Düren $M$, Morita $E$, Higgins $C$, Duh $Q Y$, Siperstein $A E$, et al. Reoperation for persistent or recurrent primary hyperparathyroidism. Arch Surg. 1996;131(8):861-7; discussion 867-9.

17. Bilezikian JP, Khan AA, Potts JT Jr; Third International Workshop on the Management of Asymptomatic Primary Hyperthyroidism. Guidelines for the management of asymptomatic primary hyperparathyroidism: summary statement from the Third International Workshop. J Clin Endocrinol Metab. 2009;94(2):335-9.

18. Irvin GL 3rd, Solorzano CC, Carneiro DM. Quick intraoperative parathyroid hormone assay: surgical adjunct to allow limited parathyroidectomy, improve success rate, and predict outcome. World J Surg. 2004;28(12):1287-92.

19. Barczynski M, Konturek A, Hubalewska-Dydejczyk A, Cichon S, Nowak W. Evaluation of Halle, Miami, Rome, and Vienna intraoperative $\mathrm{PTH}$ assay criteria in guiding minimally invasive parathyroidectomy. Langenbecks Arch Surg. 2009;394(5):843-9.

20. Fraker DL, Harsono H, Lewis R. Minimally invasive parathyroidectomy: benefits and requirements of localization, diagnosis, and intraoperative PTH monitoring long-term results. World J Surg. 2009;33(11):2256-65.

21. Smith N, Magnuson JS, Vidrine DM, Kulbersh B, Peters GE. Minimally invasive parathyroidectomy: use of intraoperative para- thyroid hormone assays after 2 preoperative localization studies. Arch Otolaryngol Head Neck Surg. 2009;135(11):1108-11.

22. Barczynski M, Konturek A, Cichon S, Hubalewska-Dydejczyk A, Golkowski F, Huszno B. Intraoperative parathyroid hormone assay improves outcomes of minimally invasive parathyroidectomy mainly in patients with a presumed solitary parathyroid adenoma and missing concordance of preoperative imaging. Clin Endocrinol (Oxf). 2007;66(6):878-85.

23. Gil-Cárdenas A, Gamino R, Reza A, Pantoja JP, Herrera MF. Is intraoperative parathyroid hormone assay mandatory for the success of targeted parathyroidectomy? J Am Coll Surg. 2007;204(2):286-90.

24. Jacobson SR, van Heerden JA, Farley DR, Grant CS, Thompson $\mathrm{GB}$, Mullan BP, et al. Focused cervical exploration for primary hyperparathyroidism without intraoperative parathyroid hormone monitoring or use of the gamma probe. World J Surg. 2004;28(11):1127-31.

25. Lew JI, Solorzano CC, Montano RE, Carneiro-Pla DM, Irvin GL 3rd. Role of intraoperative parathormone monitoring during parathyroidectomy in patients with discordant localization studies. Surgery. 2008;144(2):299-306.

26. Chen $\mathrm{H}$, Pruhs $\mathrm{Z}$, Starling JR, Mack E. Intraoperative parathyroid hormone testing improves cure rates in patients undergoing $\mathrm{mi}-$ nimally invasive parathyroidectomy. Surgery. 2005;138(4):583-7; discussion 587-90.

27. Emmolo I, Corso HD, Borretta G, Visconti G, Piovesan A, Cesario $F$, et al. Unexpected results using rapid intraoperative parathyroid hormone monitoring during parathyroidectomy for primary hyperparathyroidism. World J Surg. 2005;29(6):785-8.

28. Smith D, Murray BF, McDermott E, O'Shea D, McKenna MJ, McKennaTJ. Hungry bones without hypocalcaemia following parathyroidectomy. J Bone Miner Metab. 2005;23(6):514-5.

29. Arnault V, Beaulieu A, Lifante JC, Sitges Serra A, Sebag F, Mathonnet $\mathrm{M}$, et al. Multicenter study of 19 aortopulmonary window parathyroid tumors: the challenge of embryologic origin. World $\mathrm{J}$ Surg. 2010;34(9):2211-6.

30. Okuda I, Nakajima Y, Miura D, Maruno H, KohnoT, Hirata K. Diagnostic localization of ectopic parathyroid lesions: developmental consideration. Jpn J Radiol. 2010;28(10):707-13. 